\title{
ir
}

\section{OBSERVACIONES SOBRE LA RECEPCIÓN DE FINEZA CONTRA FINEZA DE CALDERÓN: REPRESENTACIÓN Y LECTURA}

\author{
Beatriz Mariscal Hay \\ El Colegio de México \\ [Anuario calderoniano (ISSN: 1888-8046), 1, 2008, pp. 269-283]
}

«Muérdase el diablo, que yo no quiero morderme ni hacer finezas detrás de una estera, donde de nadie soy visto que pueda alabar mi honrosa determinación» declara Berganza en El coloquio de los perros, cuando su compañero Cipión le exige que cumpla con lo que él mismo ha prescrito para evitar la murmuración ${ }^{1}$.

El concepto de fineza, tan caro a las clases privilegiadas de los españoles de los Siglos de Oro, define a una de esas prácticas sociales con las que la nobleza y cortesanos con aspiraciones buscaban señalarse, separándose del vulgo. El guiño de Cervantes al ponerlo en boca de su apicarado perro, nos lleva a cuestionar el sentido que podían haberle dado a Fineza contra fineza de Calderón, por un lado, los lectores de comedias y por otro, el público que la vio representada a fines de ese siglo y principios del siglo XVIII, lo mismo en palacio que en los corrales de la Cruz y del Príncipe 2 .

${ }^{1}$ Cervantes, El coloquio de los perros, en Novelas ejemplares, ed. J. Rodríguez Luis, p. 250. El énfasis es mío.

${ }^{2}$ La información de que se llevaron a cabo esas representaciones aparece en Varey y Shergold, 1989; Shergold y Varey, 1982. 
Si bien Fineza contra fineza es una de las piezas compuestas por Calderón para ser representadas en la corte y no ante el público llano, tenemos que considerar que tuvo una recepción bastante amplia, dado el número de ediciones que se conocen de esa obra, además de que, en mi opinión, no es posible pensar que Calderón no tomara en cuenta que su comedia sería representada ante un público no aristocrático después, claro está, de que hubiera cumplido con su primera intención de asombrar y deleitar a los monarcas y a la nobleza, además de que sería leída, si bien ese tipo de recepción de sus obras le parecía limitado, ya que el texto escrito «no puede dar de sí ni lo sonoro de la música, ni lo aparatoso de las tramoyas» ${ }^{3}$.

A la fecha, que yo sepa, no se han localizado manuscritos de Fineza contra fineza, pero tenemos una idea aproximada de la fecha de composición de la obra gracias a una carta que escribió el 30 de diciembre de 1671 el emperador Leopoldo I a su embajador en España, F. E. Von Pötting, en la que le dice que el 22 de diciembre de ese año, con motivo del cumpleaños de la reina Mariana, su hermana mayor y madre de su esposa, había hecho representar en su palacio de Viena una comedia «recientemente» compuesta por Calderón ${ }^{4}$.

Además de cumplir con el reiterado deseo de su esposa María Margarita de que hiciera traer de España música y comedias para que se representaran en la corte de Viena ${ }^{5}$, con esa puesta en escena de una obra nueva de Calderón celebraba el emperador tanto el cumpleaños de su suegra y hermana ${ }^{6}$, como el aniversario de su matrimonio con la infanta de España, quien había llegado a Viena el 5 de diciembre de 1666 acompañada por el Duque de Alburquerque.

La representación palaciega de Fineza contra fineza en Viena sería, por tanto, el punto de partida de la recepción de esa pieza dramática

${ }^{3}$ Calderón de la Barca, Preliminares a sus Autos sacramentales, alegóricos y historiales, Madrid, 1677.

${ }^{4}$ Ver Reyes, 1997, pp. 116-119.

${ }^{5}$ Son varias las cartas del emperador solicitando música y comedias españolas al embajador Pötting quien aparentemente le enviaba pocos textos de comedias y de música profana, por lo que, después de recibir una partida de villancicos, Leopoldo le pide que envíe a Viena "tonos humanos», específicamente: «a solo, dos y tres», así como comedias, que su esposa le pide vehementemente. Comp. Sullivan, 1983.

${ }^{6}$ Con ese mismo motivo se había representado en 1668, en palacio, Darlo todo $y$ no dar nada de Calderón. 
de Calderón ${ }^{7}$, de la que afortunadamente tenemos un registro que da cuenta del contexto dramático completo, ya que Leopoldo I mandó imprimir una relación de la puesta en escena y envió varios ejemplares a Madrid ${ }^{8}$.

El matrimonio de Leopoldo I con la infanta María Margarita dio un evidente impulso a la dramaturgia española en Viena, la cual se nutría además de obras que llegaban a través de los Países Bajos, generalmente traducidas 9 . En lo que concierne al teatro de Calderón, Martin Franzbach cree que junto con Fineza contra fineza llegó a Viena El gran duque de Gandía, compuesta por Calderón para celebrar la canonización de San Francisco de Borjia, que tuvo lugar el 12 de abril de 1671. No hay certeza de que Leopoldo I haya comisionado la creación de esas obras para ser representadas en Viena; Franzbach considera que cuando menos la segunda sí lo fue, ya que el tema era de interés para el emperador, en razón de la cercanía del duque de Gandía con Carlos V, antecesor de las dos casas de los Habsburgo, mientras que de la primera no hay registro de una representación madrileña anterior a $1671^{10}$.

Además de esas dos primicias del teatro de Calderón, ese mismo año se representó en Viena otra obra suya, la comedia de enredos El

${ }^{7}$ Ver Reichenberger, 1979-1981, vol. 1, pp. 264-267.

${ }^{8}$ Fineza contra fineza. Comedia, con que festeja los felices años de la Serenísima Reina de España D. Mariana de Autria, de orden de sus Majestades Cesáreas los Augustísimos Leopoldo y Margarita, el Excelentísimo Señor Marqués de los Balbases, Embajador de España [...] En 22 de diciembre de 1671. Compuesta por D. Pedro Calderón de la Barca, Caballero de la Orden de Santiago. En Viena de Austria, en la Emprenta de Matheo Cosmorovio, Impresor de S.M. Cesárea. Hay ejemplares del libro en las Bibliotecas de Londres, de Bolonia, de Mldá Vozice, y del Palacio de Cesky Krumlov. Sullivan (1983) informa haber encontrado, en la Stadsbiblioteek de Amberes una impresión de 1760 de Fineza contra fineza muy parecida a la princeps, que incluye los mismos entremeses intercalados y la misma loa a la que se agregan dos personajes. En su estudio de las comedias cortesanas, Margaret Greer, 1991, señala la importancia de considerar el contexto teatral en el que se representaban esas piezas para comprender la polivalencia del discurso dramático de Calderón, injustamente calificado como discurso del poder en tanto unívocamente laudatorio de la Corona.

9 En Barroco español y austriaco, 1994, hay dos importantes contribuciones a este tema: Reyes y Sommer-Mathis.

${ }^{10}$ Franzbach, 1982.Vaclav Cerny localizó en 1958 los manuscritos de El gran duque de Gandía y de No hay que creer ni en la verdad, en la biblioteca del castillo de los condes de Harrach en Checoeslovaquia. Comp. Sullivan, 1983, pp. 97-98. 
secreto a voces, que fue puesta en escena en el mes de febrero, durante las fiestas de carnaval, por el embajador español, el Marqués de Balbases. Aparentemente, esas representaciones, actuadas por criados españoles, llegaron a causar disturbios en la Favorita, residencia de la emperatriz viuda Eleonora, en los alrededores de Viena ${ }^{11}$.

Un segundo registro de una fiesta palaciega en la que se representó Fineza contra fineza data de $1717^{12}$. Se trata de una relación, seguramente impresa en Madrid, de la fiesta que tuvo lugar en el palacio del embajador de Portugal en España con motivo del nacimiento del infante Pedro, quinto hijo de João V de Portugal. Estas dos relaciones que incluyen las piezas menores con las que se presentó la comedia, nos permiten apreciar el paso del momento de esplendor del teatro áureo al de su decadencia, como señala Mercedes de los Reyes en su excelente estudio comparativo de esas dos representaciones palaciegas de la comedia de Calderón.

Mi propuesta es que no sólo el significado de esta obra de Calderón no habrá sido el mismo para quienes la vieron en el estreno de 1671 y quienes la vieron en 1717, a pesar de que ambas representaciones se dieron dentro del contexto de fiestas palaciegas, aunque con diferentes textos intercalados (loas, entremeses, baile y mojiganga), es evidente que tampoco lo debe de haber sido para quienes la vieron en los corrales, acompañada de otros textos y a menudo con recursos escénicos muy diferentes y, menos aún, para quienes se limitaron a leerla sin verla representada.

Germán Vega García-Luengos ha venido insistiendo en sus estudios en la importancia que tuvo la difusión impresa de las comedias de Calderón, señalando que fue el autor de textos ficcionales más leído de los Siglos de Oro, desde las primeras ediciones de sus obras en 1630 hasta el primer tercio del siglo XIX, incluyendo a Lope de Vega, Góngora, Quevedo y aun al mismo Cervantes ${ }^{13}$.

El significado que pudo haber tenido para quienes leían esa pieza dramática como relato, que incluye sólo breves acotaciones escénicas que, a modo de fragmentos descriptivos dentro de otros relatos de fic-

${ }^{11}$ La noticia aparece en una de las cartas de Leopoldo I al embajador Pötting. Comp. Reyes, 1997, p. 119.

12 Fiesta que se representó al Nacimiento de el Serenísimo Señor Infante Don Pedro...

${ }^{13}$ Vega García-Luengos, 2002. 
ción, no hacen más que situar la acción en un bosque o jardín, o indicar entradas y salidas de personajes y acciones que casi siempre cuentan con su reiteración textual, es indudablemente el menos estudiado, aunque no el menos común, por lo que me interesa contrastar estas diferentes modalidades de recepción de la comedia que nos ocupa.

Así como cada representación escénica de una comedia podía ser diferente de las otras, los textos mismos variaban de una impresión a otra. En el caso de libros que incluían varias piezas dramáticas de distintos autores o bien los que estaban compuestos por las de un solo autor, como es el caso de las Partes de Calderón, el texto de cada comedia era completo e independiente de los otros textos, lo que le daba una cierta independencia significativa, en contraste con el texto representado o impreso junto con las loas, entremeses y dedicatorias que lo acompañaban.

A esas lecturas de piezas dramáticas dedicadas por lo general a públicos más selectos ya que su costo no estaría al alcance de cualquiera, debe agregarse la lectura en ejemplares preparados para una representación o bien publicadas en medios más populares que las emparentaban con otros relatos poéticos de ficción en estilo directo como podían ser los romances ${ }^{14}$.

Todas esas posibilidades de representación, de publicación y de lectura de las piezas dramáticas del Siglo de Oro nos lleva a considerarlas no como textos clausurados por el autor, sino abiertos, reinterpretables como pieza escénica o como relato, además de que esas reinterpretaciones, como sabemos, podían modificar el texto original ${ }^{15}$. Al igual que la poesía tradicional, el texto dramático áureo llegó a contar con una existencia fluida. En la creación/recreación de los textos dramáticos participaban el primer autor, el copista e impresores de los textos que podían servir para la puesta en escena, el autor o empresario que podía modificarla de acuerdo con su propia percepción o con su programa de representación, los autores de las piezas menores que acompañaban a la obra en una representación determinada,

14 Moll, 1983, señala que había mucha disponibilidad de impresos para que las compañías representaran las comedias, además de numerosas ediciones muy poco cuidadas de sueltas.

15 Egido se refiere a esa apertura textual en su edición de La fiera, el rayo y la piedra de Calderón de la Barca. 
los impresores y editores de sueltas en compendios de varios autores o de partes con obras de un sólo autor, destinadas a la lectura más que a la representación escénica: todos ellos parte del proceso de apropiación y transmisión de una pieza dramática.

Con esa idea, en este breve trabajo contrasto algunos aspectos de la recepción de Fineza contra fineza con base en las dos relaciones de las fiestas palaciegas en que se presentó, una de ellas su primera edición (1671) y la otra, posterior a la muerte de Calderón (1717), además de su edición en la Cuarta parte de comedias nuevas de don Pedro Calderón de la Barca ${ }^{16}$, que constituye la segunda edición de la comedia, y que fue publicada en 1672, supuestamente, para ofrecer al público versiones de las piezas de Calderón depuradas de errores, con lo que se constituye en un ejemplo de texto para ser leído ${ }^{17}$.

La composición de las relaciones de ambas fiestas palaciegas es formalmente la misma, se inician con la dedicatoria al ilustre auditorio por medio de una loa escrita explícitamente para esa ocasión y a continuación el texto de la comedia intercalado con los entremeses. En el caso de la fiesta de 1717, además de una serie de textos adicionales de los que hablaremos más adelante, entre la segunda y tercera jornada se presentó un baile y al final una mojiganga.

En la loa con que se inicia le fiesta vienesa se discute quién tiene derecho a celebrar el cumpleaños de la reina Mariana, España o Alemania, dado que si bien había nacido en Alemania, era reina de España ${ }^{18}$. Puesto que ambas tienen igual derecho, lo importante será que se celebre con una comedia española de tema amoroso, Fineza contra fine$z a$. La loa cumple con su propósito de alabar a la festejada y al noble

16 He consultado la Cuarta parte de comedias del célebre poeta español don Pedro Calderón de la Barca que nuevamente corregida publica don Juan de Vera Tassis y Villarroel, en Madrid por Francisco Sanz, 1688 (microfilm del libro que posee la Universidad de Pennsylvania). Hesse, 1948 contrasta el texto de la comedia en las dos ediciones de la Cuarta parte de comedias y da cuenta detallada de las enmiendas y omisiones que presenta la segunda de ellas.

${ }^{17}$ En esa edición, a pesar de que la comedia aparece sin indicaciones sobre el escenario y en general las didascalias son muy pocas, en la tabla de contenidos se indica que Fineza contra fineza es una «fiesta que se representó ante sus majestades». Tenemos noticia de su representación en palacio por la compañía de Simón Aguado el 3 de diciembre de 1682. Ver Varey y Shergold, 1982 y 1989.

18 No se señala quién es su autor, como tampoco se señala el origen de los entremeses que acompañan a la comedia. 
auditorio, siendo ellos mismos un elemento importante de la representación de la comedia ${ }^{19}$. Las otras piezas que la acompañan, los entremeses de Orfeo y Eurídice y de La novia barbuda, podrían haber llegado a Viena con cualquier otro envío de piezas españolas ${ }^{20}$. El tono de los entremeses es jocoso: el primero, un «entremés en música» compuesta por el propio Leopoldo ${ }^{21}$, trata de forma paródica y hasta picante el mito de Orfeo y Eurídice, haciendo burla del tema del amor de la comedia, algo que también hace el segundo entremés de La novia barbuda ${ }^{22}$.

El público de comedias estaba acostumbrado a ver estos paréntesis cómicos con los que se intercalaba una comedia, o inclusive una tragedia, la pieza de Calderón tiene además su contrapunto cómico en las intervenciones de Lelio, criado de Celauro, quien después de un disparatado diálogo amoroso con Libia quien no pone ninguna resistencia a sus avances y acepta hablar con él cuando quiera, ya que ella escucha a cualquiera, exclama:

¡Qué constancia, y qué valor

tan heroico, y singular!

¡Oh qué gran cosa es amar

a damas de pundonor!

Con lo que subvierte el valor de las relaciones amorosas de los nobles a las que responden las finezas de amor y abre una salida diferente a la interpretación ortodoxa de la comedia en la que los cuatro protagonistas principales compiten por hacer la mayor fineza de

${ }^{19}$ Neumeister, 1995, opina que una representación de esa obra exigiría que participaran los príncipes en su carácter de público, como parte de la puesta en escena. Ver además el estudio de Varey sobre las Etiquetas de palacio que detallan la disposición de la familia real y su entourage durante las representaciones palaciegas en su artículo de 1968.

${ }^{20}$ Ni Sullivan ni Franzbach creen que Calderón haya sido su autor.

${ }^{21}$ Ver Varey, Introducción a su edición de Los celos hacen estrellas de Juan Vélez de Guevara, en la que cita la carta del emperador, p. cvi. De gran interés es el estudio de Sage sobre «La música de Juan Hidalgo para Los celos hacen estrellas de Juan Vélez de Guevara" que constituye el apéndice III, pp. 169-273, de esa edición.

22 Reyes, 1997, pp. 123-126. 
amor $^{23}$. De hecho, el triunfo de Venus y el amor frente a Diana y el recato, que desarrolla Fineza contra fineza, constituye en sí una propuesta subversiva de las estructuras sociales del momento, dominadas como estaban por el celo religioso, según ha propuesto Marlene Collins ${ }^{24}$. Ello no obstante, en la obra, si bien se concede imperio al amor, no deja de aclararse que se trata de la variante de amor «digno", tal y como insiste Anfión:

\author{
Que tampoco \\ soy tan bárbaro que intente \\ que los deleites de Venus \\ sean no dignos deleites.
}

Para el público cortesano, una reiteración de que el amor puede ser parte de una conducta honorable, por lo que no hay necesidad de negarlo, y para el público menos preocupado por el código de las finezas de amor y de honor, un mensaje más abierto sobre la importancia de dar al amor su lugar ya que se trata de un instinto natural ${ }^{25}$.

Como venimos insistiendo, las piezas menores que se representaron durante las fiestas palaciegas debieron influir, cada una a su manera, en la interpretación de la comedia por parte del público cortesano ahí presente, pero la diferencia mayor entre las dos fiestas palaciegas está en el lugar que se otorga a la obra de Calderón en relación con los otros textos que aparecen en las dos relaciones impresas de la fiesta. Mientras que en la relación vienesa el título de la comedia es lo primero que se lee en la portada, antes que el nombre de la festejada: Fineza contra fineza. Comedia con que festeja los felices años de la Serenísima Reina de España D. Mariana de Austria..., en la de la fiesta de Madrid el título no aparece en la portada. Se habla de fiesta, de que se celebra el nacimiento del infante don Pedro, hijo de los reyes de Portugal don João V y Mariana Josefa de Austria, y de que tiene lugar en el palacio del embajador en Madrid, don Pedro de Vasconcellos, en

${ }^{23}$ Ver O'Connor, 1992, donde propone que no podemos hablar del honor como un sistema unívoco de conducta en el teatro de Calderón, sino más bien como una red de conceptos e ideales.

24 Collins, 2005.

25 O'Connor, 2002, p. 161 señala que Calderón propone que las finezas amorosas y cortesanas constituyen la más alta manera de cumplir con el estamento noble. 
ningún lado aparece ni el título de la comedia ni el nombre de su autor.

La relación de 1717 comienza con dos sonetos, uno en español a modo de dedicatoria al monarca y otro en portugués, ambos seguramente concebidos para ser publicados, ya que el segundo es un acróstico que forma el nombre del embajador Vasconcellos, patrocinador del evento. Sigue la loa, firmada por Josef de Cañizares, en la que se enaltece al monarca portugués. También en contraste con la fiesta vienesa, la que tiene lugar en el palacio del embajador de Portugal en Madrid contó con un complicado montaje escénico concebido no para la comedia, sino para la loa con que se inicia la representación.

Lo primero que aparecía en el escenario era una gran cortina «de primorosa pintura», con Marte en su carro arriba en un lado y Venus con el suyo en el opuesto, Cupido, Lealtad y Fama, cada uno con una estrella en la mano representando, según explicaba una tarja, las cinco quinas del escudo de armas de Portugal ${ }^{26}$. Frente a esa cortina se representó la primera parte de la loa, mientras que, para la segunda parte, se "desvanecía» la cortina y aparecía un cuadro en el que participaban un Atlante cargando un orbe con el escudo de armas de Portugal, Lusitania sentada en un trono, Marte de rodillas frente a ella, además de Amor, Juno, Cibele, Océano, cinco figuras que representaban provincias portuguesas y Venus "vestida a lo indio» con su ofrenda de corales, perlas, oro y perfumes, cada uno con un escudo que llevaba una gran letra con que se deletreaba el nombre de los reyes de Portugal, D. JUAN y MARÍA.

La loa terminaba con todos cantando a coro:

El uno aumenta su celo, otro da al cetro firmeza, con que en amoroso duelo

${ }^{26}$ En 1714 se pagaron 4800 reales de vellón a Antonio Palomino por pintar el telón que acompañaba la loa de una representación palaciega. En 1707, con motivo del nacimiento del príncipe Luis I, se pintó un telón relacionado igualmente con la loa, en la que se juega con números y cifras como en la loa de 1717. Otras similitudes se pueden encontrar con la loa de Cañizares representada frente a un telón pintado, en marzo de 1720 para celebrar el nacimiento del infante Felipe. Ver López Alemany y Varey, 2006. 
lidian Portugal y el cielo, fineza contra fineza.

Después de la comedia, presentada "con teatro de bosque», una mojiganga cierra la representación. A continuación aparecen impresos cuatro textos más: un soneto dedicado al rey de Portugal, celebrando el nacimiento del infante Pedro y la construcción de la catedral, una glosa, compuesta por Francisco Diego de Acuña y Vasconcelos, nuevamente el soneto en acróstico que aparecía al principio del libro y su glosa compuesta también por Francisco de Acuña.

Con todos estos elementos escénicos y textuales que engloban a la comedia, colocados antes y despés de la obra de Calderón, los monarcas portugueses se incrustan visual y textualmente en la comedia. En ese contexto de representación visual y auditiva, la trama de Fineza contra fineza se inicia y termina con la exaltación del rey de Portugal y con el lugar que ocupa con respecto a Dios, con quien se puede poner al tú por tú en finezas.

Añádase a ésto el hecho de que el coro cierra la loa y abre la comedia, con lo que también la música une esos elementos en escena.

Para quienes hayan visto la representación de la pieza de Calderón en el palacio del embajador Vasconcellos o hayan leído la relación, el contexto escénico y literario tiene que haber sido impresionante, con lo que las finezas que realizan los protagonistas de la comedia, bien sean de amor, bien sean de honor, terminan por aparecer como representaciones de finezas del monarca portugués.

Cabe señalar que en 1671, cuando Calderón compuso Fineza contra fineza, en Portugal era regente el futuro Pedro II, quien se había casado con María Francisca de Saboya, ex-esposa de su hermano Afonso VI. El matrimonio de María Francisca con el rey de Portugal había tenido que ver precisamente con los intereses de sucesión al trono español por parte de Francia, en contra de los intereses de la casa de Austria que representaba la reina Mariana, con lo que el aparato de la fiesta y el aprovechamiento de la obra de Calderón para exaltar en España al rey de Portugal cuando fue compuesta la comedia hubiera sido, aún en casa de su embajador, cuando menos, cuestionable.

En contraste, en 1717, las hostilidades entre España y Portugal habían cesado y Portugal gozaba de un período de auge gracias a las riquezas extraídas de Brasil. En cuanto a la selección precisamente de esa obra de Calderón para la fiesta en casa del embajador Vasconcellos, 
está el hecho de que el celebrado rey de Portugal era João V, quien estaba casado con Mariana Josefa de Austria, hija de Leopoldo I de Austria, patrocinador de la primera representación y publicación de Fineza contra fineza.

En sus diversos estudios sobre el teatro áureo,Varey y Shergold consignan hasta catorce representaciones de Fineza contra fineza, dos de ellas en palacio, el 3 de diciembre de 1682 y el 25 de febrero de 1685. Entre las representaciones más cercanas a la fiesta en la embajada de Portugal están las que tuvieron lugar en el corral del Príncipe del 21 al 23 de abril de 1717 y la del 12 de septiembre de ese mismo año, además de la representación del 13 de junio de 1718. La cercanía de esas presentaciones con la fiesta palaciega nos lleva a pensar que es probable que la misma compañía que representó la obra en el corral lo hizo en la embajada, inclusive, con las mismas piezas secundarias: el Entremés de las gitanas, el Baile del órgano y una mojiganga ${ }^{27}$, apropiadas a las fiestas de Corpus ${ }^{28}$.

Pasemos a considerar brevemente la diferente percepción de la obra que pueden haber tenido sus lectores, ya que, si bien no deja de ser una pieza dramática, leída, varias de las acciones que tienen importancia escénica, tienen un carácter meramente incidental en la intriga narrativa.

Para la fábula del relato, el mito es esencial, ya que constituye el antecedente causal que termina por provocar la acción con que se inicia la obra dramática. La cadena causal tiene como punto de partida la muerte de Anteón, padre de Anfión, convertido en ciervo por Diana y destrozado por sus propios perros, una tragedia provocada por la casualidad que lo llevó al sitio donde se bañaba desnuda la diosa, provocando su ira y su venganza: «se vengó como si fuese delito el acaso», señala Anfión. Más allá del mito, parte importante de la explicación de las razones que llevan a Anfión a la conquista de Tesalia son una serie de reflexiones sobre la necesidad de que quien establece las leyes las cumpla, algo que no hizo la diosa ya que se entregó al pastor Endimión; sobre la hipocresía: no está bien «que se callen los favores

27 Esta mojiganga fue representada en la fiesta de Corpus de 1716 por las compañías de Juan Álvarez y José del Prado. Comp. Reyes, 1997, p. 133.

${ }^{28}$ Ver Reyes, 1997, pp. 13-136. Varey y Shergold, 1982, 1989, 1992 y 2006. 
y se digan los desdenes» y sobre el arte de gobernar: hay que mantener lo conquistado antes de conquistar de nuevo.

En escena, donde la palabra no es más que uno de los elementos significativos, siendo los otros las acciones, el escenario y la música, no tienen mucha importancia, son parte solamente de un hermoso y largo discurso del guerrero vencedor, un «indicio» de que lo mueven sentimientos nobles, de que no es un «bárbaro» y, por tanto, va a ser capaz de actuar con piedad. Es más bien una caracterización del personaje que una causa dentro de la trama representada ${ }^{29}$.

La acción dramática, en contraste con la fábula narrativa marcada por antecedentes y reflexiones, comienza con ruido de cajas y trompetas y con la aparición de un general que ha derrotado a su enemigo y que al momento de hacer que prendan fuego al templo de Diana, se enfrenta con sus sacerdotizas, quienes a coro y acompañadas de música le suplican piedad. Una escena de fuerte contraste visual y auditivo entre el fiero guerrero vencedor y las hermosas ninfas vencidas que cantan su súplica y lamento.

Otro momento de importante carga dramática de la comedia que puede servirnos de ejemplo de las diferencias entre el texto dramático y el texto poético narrativo es el encuentro entre Doris y Celauro cuando la ninfa va al jardín donde solían encontrarse de noche, convencida de que su amante ha muerto. Acompañada de Libia, se lamenta la muerte de Celauro y habla con el viento y sus fantasmas. Celauro llega al jardín y en la escasa luz de las estrellas y luceros descubre dos bultos, reconoce la voz de Doris, pero como no sabe con quien está, se esconde. Cuando Celauro por fin se acerca y habla a su amada, provoca pánico en ambas y Doris se desmaya. Celauro se esconde entre las ramas, llegan otras sacerdotisas y se llevan a Doris desmayada.

En términos del texto escrito, se trata de uno de esos encuentrosdesencuentros propios de las comedias de enredo, que poco hacen avanzar la intriga, ya que el personaje que no está al tanto de los verdaderos acontecimientos continúa sin conocer la verdad, en contraste

${ }^{29}$ Greer, 1991, p. 179, considera que esta pieza de Calderón es diferente a las otras comedias palaciegas de tema mitológico, ya que en ella los dioses son personajes marginales que intervienen sólo brevemente en la representación. De hecho, el único que actúa es Cupido, y efectivamente no hace más que ratificar una decisión ya tomada por Anfión; las diosas son sólo estatuas. 
con el público que ve lo que sucede. La unión de los amantes va a depender de hechos ajenos a ellos, puesto que para salvar la vida de Diana, a quien la fortuna le es adversa a la hora de pagar el agravio de que hayan sustraído la estatua de Venus del altar, no basta con el amor y finezas de Celauro, quien no puede revelar el nombre de la verdadera culpable, ya que, como él mismo señala, «el cielo no permite que el noble mienta", ni siquiera para salvar la vida de su amada.

Calderón, al igual que los otros dramaturgos, escribía comedias para ser representadas en escena, pero también las escribía para ser impresas como consta por su preocupación por depurar los textos de sus piezas dramáticas cuando iban a ser publicadas en Partes, dejando testimonio de que él se encargaría de revisarlas (aunque no lo haya hecho en su totalidad) ya que consideraba que sus textos habían sido «adulterados» por diversos editores, además de que muchos habían sido erroneamente atribuidos a otros autores, a la vez que los de otros autores habían sido atribuidos a él.

Si en escena Fineza contra fineza podía servir para exaltar a los monarcas, lo mismo españoles que extranjeros, para «educar» a los nobles y a los poderosos si es que la consideramos dentro de la controversia de la licitud del teatro, como propone Thomas O'Connor y, como tal, como una defensa de su vida como dramaturgo, como una apología pro vita sua $a^{30}$, leída, como la habrán conocido una parte importante de sus receptores, sería una historia de actos de valor y de amor que se inician con una casualidad, un juego más de la loca fortuna que interviene a cada momento y que impide la recuperación del imperio de la diosa de la luna al provocar una tormenta que destruye la armada que llega para salvar a Tesalia de los adoradores de Venus. Una fábula con acciones y situaciones cuidadosamente encadenadas causalmente y enriquecida con propuestas y reflexiones sobre la casualidad y la hipocresía, sobre las consecuencias de ambas y, claro está, sobre la necesidad del amor, en todas sus modalidades.

30 O’Connor, 2002. 


\section{Bibliografía}

Calderón de la Barca, P., Cuarta parte de comedias del célebre poeta español don Pedro Calderón de la Barca que nuevamente corregida publica don Juan de Vera Tassis y Villarroel, en Madrid por Francisco Sanz, 1688. (Microfilm del libro que posee la Universidad de Pennsylvania).

- La fiera, el rayo y la piedra, ed. A. Egido, Madrid, Cátedra, 1989.

- Preliminares a sus Autos sacramentales, alegóricos y historiales, Madrid, Buendía, 1677.

Cervantes, M. de, El coloquio de los perros, Novelas ejemplares, ed. J. Rodríguez Luis, Madrid, Taurus, 1983.

Collins, M., «Subversive Demythologizing in Calderón de la Barca's Fineza contra fineza: The Metamorphosis of Diana», Hispanic Review, 73-3, 2005, pp. 275-290.

Fiesta que se representó al nacimiento del serenísimo señor infante don Pedro, hijo de los muy altos y muy poderosos señores don João el $V y$ doña Mariana Josefa de Austria, reyes de Portugal Ec. En el palacio del excelentísimo señor don Pedro de Vasconcelos, del Consejo de Guerra de su majestad, maestro de campo general de sus ejércitos y su embajador extraordinario en esta corte de Madrid, el domingo 12 de septiembre de 171, s. $1 . y$ s. a.

Franzbach, M., El teatro de Calderón en Europa, Madrid, Fundación Universitaria Española, 1982.

Greer, M. R., The Play of Power. Mythological Court Dramas of Calderón de la Barca, Princeton, New Jersey, Princeton University Press, 1991.

Hesse, E. W., «The First and Second Editions of Calderón's Cuarta parte», Hispanic Review, 16, 3, 1948, pp. 209-237.

López Alemany, I. y J. E. Varey, El teatro palaciego en Madrid: 1707-1724, London, Tamesis, 2006.

Moll, J., "Sobre las ediciones del siglo XviI de las partes de comedias de Calderón», en Calderón. Actas del Congreso Internacional sobre Calderón y el Teatro Español del Siglo de Oro, ed. L. García Lorenzo, Madrid, CSIC, 1983, vol. I, pp. 221-234.

Neumeister, S., «Una comedia palaciega en representación particular: Fineza contra fineza de Calderón», Cuadernos de teatro clásico, 8, 1995, pp. 30-42.

O’CONNOR, T. A., «La gramática y retórica del honor calderoniano: las finezas como principio substancial», en Actas del X Congreso de la Asociación Internacional de Hispanistas, Barcelona, PPU, 1992, vol. 2, pp. 1045-1052.

- "Calderón y la censura: Fineza contra fineza como una apología pro vita sua», en Ayer y hoy de Calderón. Actas seleccionadas del Congreso Internacional celebrado en Ottawa del 4 al 8 de octubre del 2000, Madrid, Castalia, 2002, pp. 155-168. 
Reichenberger, K. y R., Bibliographisches Handbuch der Calderón Forschung/ Manual bibliográfico calderoniano, Kassel, Thiele und Schwarz, 1979-1981, vol. 1.

REYES, M. de los, «Relaciones teatrales españolas y austriacas durante el reinado de Leopoldo I y Margarita de Austria (1663-1673)», en Barroco español y austriaco: fiesta y teatro en la Corte de los Habsburgo y los Austrias, ed. J. M. Díez Borque y K. F. Rudolf, Madrid, Ayuntamiento de Madrid, 1994, pp. 59-66.

- «El teatro barroco en las cortes europeas: las representaciones de Fineza contra fineza en Viena (1671) y en Madrid (1717)», en Actes du Congrès International Théatre, Musique et Arts dans les Cours Européennes de la Renaissance et du Baroque, Varsovie, Université de Varsovie, 1997, pp. 145178.

Shergold, N. D. y J. E. Varey, Representaciones palaciegas: 1603-1699. Estudios $y$ documentos, London, Tamesis, 1982.

Sommer-Mathis, A., "Las relaciones teatrales entre las dos ramas de la Casa de Austria en el Barroco», en Barroco español y austriaco: fiesta y teatro en la Corte de los Habsburgo y los Austrias, ed. J. M. Díez Borque y K. F. Rudolf, Madrid, Ayuntamiento de Madrid, 1994, pp. 41-57.

Sullivan, H.W., Calderon in the German lands and the Low Countries: his reception and influence, 1654-1980, Cambridge, Cambridge University Press, 1983.

VArey, J. E., «L'Auditoire du Salón dorado de l'Alcázar de Madrid au XVII siècle», en Dramaturgie et Société, ed. J. Jacquot, Paris, CNRS, 1968, vol. 1, pp. 77-91.

- Introducción a su edición de Los celos hacen estrellas de Juan Vélez de Guevara, London, Tamesis, 1970.

VArey, J. E. y N. D. Shergold, Representaciones palaciegas: 1603-1699. Estudios $y$ documentos, London, Tamesis, 1982.

- Comedias en Madrid: 1603-1709. Repertorio y estudio bibliográfico, London, Tamesis, 1989.

- Los libros de cuentas de los corrales de comedias de Madrid: 1706-1719. Estudios $y$ documentos, London, Tamesis, 1992.

- El teatro palaciego en Madrid: 1701-1724. Estudios y documentos, London, Tamesis, 2006.

Vega García-Luengos, G., «El predominio de Calderón también en las librerías: consideraciones sobre la difusión impresa de sus comedias», en Calderón 1600-2000. Jornadas de investigación calderoniana, ed. A. González, México, El Colegio de México, 2002, pp. 15-33. 
